\title{
Incidence of probable occupational asthma and changes in airway calibre and responsiveness in apprentice welders
}

\author{
M. El-Zein*, J-L. Malo\#, C. Infante-Rivard*, D. Gautrin"
}

Incidence of probable occupational asthma and changes in airway calibre and responsiveness in apprentice welders. M. El-Zein, J-L. Malo, C. Infante-Rivard, D. Gautrin. (C) ERS Journals Ltd 2003.

ABSTRACT: The majority of cross-sectional studies have shown a higher prevalence of ventilatory impairment in welders while only few longitudinal studies were able to detect chronic effects on spirometry or bronchial responsiveness.

The aim of the study was to determine the incidence of probable occupational asthma (OA), bronchial obstruction and hyperresponsiveness among 286 students entering an apprenticeship programme in the welding profession.

This epidemiological prospective cohort study consisted of a baseline assessment survey and two follow-up assessments. A respiratory symptom questionnaire was administered at each visit. Spirometry and methacholine bronchial challenge test results, conducted once prior to onset of exposure and later after an average of 15 months of apprenticeship, were available for 194 subjects.

The incidence of probable OA was $\sim 3 \%$ (6 of 194). The incidence of bronchial hyperresponsiveness, defined as a $\geqslant 3$.2-fold decrease in the provocative concentration causing a $20 \%$ fall in the forced expiratory volume in one second from baseline to the end of the study was $11.9 \%$. A statistically significant difference was found between the baseline and end of study for the lung function values. In particular, the forced expiratory volume per cent predicted had significantly dropped by $8.4 \%$ on average.

The significance of these early pulmonary function changes in relation to possible chronic effects of exposure to welding fumes and gases remains to be explored. Eur Respir J 2003; 22: 513-518.
*Joint Depts of Epidemiology and Biostatistics and Occupational Health, McGill University, Montréal, and \#Dept of Chest Medicine, Sacré-Coeur Hospital, Montréal, Canada.

Correspondence: D. Gautrin, Dept of Chest Medicine, Sacré-Coeur Hospital, 5400 Gouin Blvd West, Montréal, H4J 1C5, Canada. Fax: 15143383123

E-mail: D-Gautrin@crhsc.umontreal.ca

Keywords: Airway hyperresponsiveness occupational asthma prospective study welders

Received: January 62003

Accepted after revision: April 132003

This study was supported by L'Association Pulmonaire du Québec. M. El-Zein is a $\mathrm{PhD}$ student funded by the Max-Stern Recruitment Fellowship, McGill University and by the McAbbie Foundation Fellowship, Université de Montréal. D. Gautrin is a research scholar with the Fonds de la recherche en santé du Québec.
Since the 1980s, epidemiological studies investigated the effects of exposure to welding fumes and gases on lung function and clinical manifestations in welders. The assessment of the effect on pulmonary function is limited, in that most studies have been cross-sectional in design, conducted in groups of welders and nonwelder referents. These studies have not consistently demonstrated an impairment of pulmonary function in occupationally exposed welders [1]. However, there is now good evidence of a higher prevalence of ventilatory impairment in welders shown by significantly lower pulmonary function indices than in comparable controls [2-9]. The confounding effect of smoking has been demonstrated $[5,6,10]$. Studies of short-term respiratory function have shown a greater reduction in lung function indices among welders than among nonwelders [3, 11].

There have been relatively few published longitudinal studies. A 2-yr follow-up study showed no significant overall difference in the annual change in pulmonary function variables between welders and nonwelders; however, smoking welders and those welding without local exhaust ventilation or respiratory protection had significantly increased risks for accelerated decline in the forced expiratory volume in one second (FEV1) [12]. This confirmed earlier findings by CHINN et al. [13] in a group of shipyard welders. A 3-yr prospective cohort study on airway reactivity in a group of shipyard workers, including 51 arc welders and 54 nonwelders, showed that welding was associated with a transient across-work-shift decrement in midflow and reversible work-related symptoms; however, no chronic irreversible effects on spirometry or bronchial responsiveness was seen over the 3 yrs [14].

Bronchial responsiveness to specific agents from the working environment and to nonspecific (methacholine or histamine) agents has not been extensively investigated in welders. A cross-sectional study on stainless-steel (SS) and mild-steel (MS) welders found that bronchial responsiveness and lung function in active welders was normal and did not differ between MS and SS welders or between welders and a reference group of vehicle assembly workers who had never welded [8].

To the best of the authors' knowledge, no prospective study of the incidence of bronchial hyperresponsiveness (BHR) has been performed in a population of welders with objective measures of bronchial responsiveness at the onset of exposure. Moreover, given the inconsistency in the previously conducted studies, further investigation on changes in bronchial responsiveness and airway obstruction, especially in asymptomatic subjects, is needed in welders starting exposure to metal fumes.

The objectives of the study were to determine, in apprentice welders: 1) the incidence of welding-related respiratory symptoms coexisting with significant BHR; 2) the incidence of BHR; and 3) the decrease in FEV1 brought about by exposure to welding fumes and gases for an average duration of 15 months. 


\section{Methods}

\section{Study design}

This epidemiological prospective cohort study consisted of a baseline assessment survey and two follow-up assessments among apprentices starting a 15-18-month training programme for a welding profession. The study was performed at four teaching institutions in the Montreal region offering the welder fitter training programme. The students practiced welding using mainly four welding processes. These were shielded metal arc welding, gas metal arc welding, flux cored arc welding and gas tungsten arc welding. The welded metals included mainly MS, SS and aluminium. Welding on galvanised steel was not performed. The overall time allocated by each school to be spent on welding using these processes corresponded on average, in reference to $8 \mathrm{~h} \cdot \mathrm{day}^{-1}$ of welding in a workshop, to $\sim 2$ months of exposure to welding fumes and gases.

A respiratory symptom questionnaire derived from the standardised questionnaire of the International Union against Tuberculosis and Lung Disease [15] was administered at baseline and at the two follow-up visits. Questions on the development of respiratory symptoms specifically during welding were added to the questionnaire. The general question was "when you are welding do you have respiratory problems?". If a positive answer was provided, the subject was asked to indicate which of the following symptom/symptoms: "coughing, wheezing (whistling), chest tightness, other".

Spirometry and methacholine tests were performed on two occasions; first before the apprentices started exposure to welding fumes and gases, and again at the end of the study. Lung function was assessed by spirometry. Spirometry was performed with a Collins-type spirometer (WE Collins, Braintree, MA, USA) according to the criteria of the American Thoracic Society [16]. Bronchial responsiveness was determined by methacholine inhalation tests. Methacholine inhalation tests were performed according to the standardised procedure [17], using a Wright nebuliser (output $=0.14 \mathrm{~mL} \cdot \mathrm{min}^{-1}$; Roxon Meditech Ltd, Montreal, PQ, Canada) at tidal-volume breathing for $2 \mathrm{~min}$. For subjects with a history not suggestive of asthma, an abbreviated protocol was used, starting with concentrations of $2 \mathrm{mg} \cdot \mathrm{mL}^{-1}$ and moving up to 8 and $32 \mathrm{mg} \cdot \mathrm{mL}^{-1}$ if there was no significant $(<5 \%)$ fall in FEV1 between inhalations [18, 19]. Otherwise, doubling concentrations of methacholine were administered at 2, 4, 8, 16 and $32 \mathrm{mg} \cdot \mathrm{mL}^{-1}$ (maximum concentration used). The provocative concentration causing a $20 \%$ decrease in FEV1 (PC20) was interpolated from individual dose/response curves drawn on a semilogarithmic scale. A baseline FEV1 of $<2 \mathrm{~L}$ or pregnancy contraindicated the test. These tests of pulmonary functions and bronchial responsiveness were performed at the teaching institutions twice: at the beginning and at the end of the welding course. These tests had also been previously performed by the authors' research team in epidemiological studies in the field, without an on-site physician and with no complications or problems occurring [19].

\section{Study subjects}

This study is part of a larger study in which 286 apprentice welders were followed for the duration of their welding training. Only students who had not been exposed to welding fumes and gases in the 2 months prior to the start of their apprenticeship and who had not welded for $>1 \mathrm{yr}$ in their lifetime were included. Of the 286 apprentices, spirometric and methacholine test results were available for 194 subjects by the end of the study. Ninety-two students $(32 \%)$ did not have these tests, as 82 discontinued their training while another eight refused to take the methacholine and spirometry tests at follow-up and two students had not undergone these tests at the onset. The participants gave written consent to undergo the study measures. This project was approved by the ethics committee of Sacré-Coeur Hospital.

\section{Study variables}

"Welding-related respiratory symptoms suggestive of occupational asthma (OA)" were present in subjects who had at least one of the welding-related symptoms, such as cough, wheezing, or chest-tightness at the first follow-up visit that persisted until the second follow-up, or the development of at least one of the above symptoms as of the second follow-up visit.

The following measurements were derived from spirometry: FEV1, forced vital capacity (FVC), and the FEV1/FVC ratio. Results were expressed as a percentage of the predicted value. Reference values of KNUDSON et al. [20] were used; abnormal results for FEV1 were set at $80 \%$ pred as this percentage corresponds to the lower limit of the $95 \%$ confidence intervals.

Significant BHR was defined as the provocative concentration, i.e. $\mathrm{PC} 20 \leqslant 8 \mathrm{mg} \cdot \mathrm{mL}^{-1}$ [17] or PC20 $\leqslant 16 \mathrm{mg} \cdot \mathrm{mL}^{-1}$ [21], to methacholine causing a $20 \%$ fall in FEV1. Changes in PC20 were considered significant when there was a two-fold or $\geqslant 3$.2-fold decrease from the baseline values [22]. Probable OA was defined as the presence of welding-related respiratory symptoms suggestive of OA (described above) with a two-fold or $\geqslant 3$.2-fold decrease in PC20 between the baseline and end of study.

The slope of the methacholine dose/response curve was used as a continuous parameter for all study subjects as recommended for population studies, since many subjects fail to experience a specified response, such as a 15 or $20 \%$ decline in FEV1 $[23,24]$. The dose/response slope was expressed by the percentage decline in FEV1/dose of methacholine, where decline was expressed as a positive value and where dose in $\mu \mathrm{mol}$ was defined as the final cumulative methacholine dose administered [18]. As the slope distribution was not normal $(p<0.0001$, Lilliefors test for normality), a logarithmic transformation of this ratio was then used. Higher positive values corresponded to more pronounced airway responsiveness.

\section{Statistical analysis}

Descriptive statistics and prevalence rates of baseline host characteristics, including measurements obtained from spirometry and bronchial challenge tests, were obtained. Incidence rates of respiratory symptoms at the first follow-up visit and at the end of the study were provided. Paired t-tests were used to evaluate changes in lung function measures from the baseline to the end of study values. A nonparametric McNemar test was used to evaluate changes in spirometric measurements (i.e. FEV1, \% pred $<80 \%$ versus FEV1, \% pred $\geqslant 80 \%$ and $\mathrm{FEV} 1 / \mathrm{FVC}$, $\%$ pred $<85 \%$ versus $\mathrm{FEV} 1 / \mathrm{FVC}$, $\%$ pred $\geqslant 85 \%$ ) as well as in bronchial responsiveness estimates (i.e. $\mathrm{PC} 20 \leqslant 8 \mathrm{mg} \cdot \mathrm{mL}^{-1}$ versus $\mathrm{PC} 20>8 \mathrm{mg} \cdot \mathrm{mL}^{-1}$, and $\mathrm{PC} 20 \leqslant 16 \mathrm{mg} \cdot \mathrm{mL}^{-1}$ versus $\left.\mathrm{PC} 20>16 \mathrm{mg} \cdot \mathrm{mL}^{-1}\right)$. Stratified analyses were performed, comparing changes in lung function measures from the baseline to the end of the study values, taking into consideration the day of the week the methacholine test was administered (Monday versus other days of the week), baseline $\mathrm{PC} 20$ ( $\mathrm{PC} 20 \leqslant 16$ versus $\mathrm{PC} 20$ $>16 \mathrm{mg} \cdot \mathrm{mL}^{-1}$ ) and smoking (current smokers versus nonsmokers). Statistical analyses were performed. The level of significance was set at $\mathrm{p} \leqslant 0.05$. 


\section{Results}

This group of apprentice welders represents a relatively young population with a mean $\pm \mathrm{SD}$ age of $24.5 \pm 7.4 \mathrm{yrs}$, dominated by males $(85.7 \%)$. Slightly more than one-third $(33.7 \%)$ had never smoked, and $50.5 \%$ were current smokers.

Table 1 shows the incidence of respiratory symptoms at the two follow-up periods as well as the results of the lung function and methacholine bronchial challenge tests at baseline and at the end of study. As shown, data are presented for 194 apprentice welders. The incidence of respiratory symptoms was similar at the first and second follow-up assessments. A statistically significant difference was found between the baseline and end of study mean values for the lung function tests. In particular, FEV1, \% pred had significantly dropped by $8.4 \%$ on average. A higher percentage of subjects had a FEV1, $\%$ pred $<80 \%$ at the end of the study compared with the baseline values $(11.3$ versus $3.6 \%, \mathrm{p}<0.01)$. A statistically significant intra-subject difference was found in the slope of the methacholine dose/response curve; the change indicated an increase in bronchial responsiveness (i.e. higher value at the end of the study). Nearly $14 \%$ of the 194 apprentices had a $\mathrm{PC} 20 \leqslant 8 \mathrm{mg} \cdot \mathrm{mL}^{-1}$, and $20 \%$ had a $\mathrm{PC} 20$ $\leqslant 16 \mathrm{mg} \cdot \mathrm{mL}^{-1}$ at baseline. These figures were higher, nearly 19 and $24 \%$, respectively, at the end of the study. The proportion of subjects with a $\mathrm{PC} 20 \leqslant 8 \mathrm{mg} \cdot \mathrm{mL}^{-1}$ at follow-up was significantly greater than at baseline.

Table 2 shows that a greater proportion of subjects $(15.2 \%)$ with baseline $\mathrm{PC} 20 \leqslant 16 \mathrm{mg} \cdot \mathrm{mL}^{-1}$ compared to subjects with baseline $\mathrm{PC} 20>16 \mathrm{mg} \cdot \mathrm{mL}^{-1}(6.5 \%)$ had a drop in FEV1, $\%$ pred $<80 \%$, although this was not significant $(\mathrm{p}=0.15)$. Having a baseline $\mathrm{PC} 20 \leqslant 8 \mathrm{mg} \cdot \mathrm{mL}^{-1}(20 \%)$ compared to a PC20 $>8 \mathrm{mg} \cdot \mathrm{mL}^{-1}(5.7 \%)$ was associated with a decline in FEV1 \% pred $<80 \%(\mathrm{p}=0.02)$ (results not shown). Then again, having a steeper slope of the methacholine dose/response curve at baseline (1.72 versus 1.53$)$ was not associated with a drop in FEV1 \% pred $<80 \%$ ( $\mathrm{p}=0.19)$ (not shown).

Conversely, when considering the decline in FEV1 in terms of mean $\%$ decline, no difference between subjects according to $\mathrm{PC} 20$ at baseline whether comparing subjects with $\mathrm{PC} 20 \leqslant 16 \mathrm{mg} \cdot \mathrm{mL}^{-1}$ to those with $\mathrm{PC} 20>16 \mathrm{mg} \cdot \mathrm{mL}^{-1}$
(-7.48 $\pm 11.44 \%$ pred versus $-8.68 \pm 8.56 \%$ pred, respectively) or when using the cut-off value of PC20 $8 \mathrm{mg} \cdot \mathrm{mL}^{-1}$ was found. In addition, no correlation was found between mean FEV1 \% decline and dose/response slope at baseline.

The pattern of change in bronchial responsiveness during the course of the apprenticeship is detailed in table 3. Nearly $7 \%$ had a 3.2-fold decrease in PC20 when they initially had a baseline $\mathrm{PC} 20>16 \mathrm{mg} \cdot \mathrm{mL}^{-1}$. On the other hand, slightly over 5\% had that decrease while their baseline PC20 was $\leqslant 16 \mathrm{mg} \cdot \mathrm{mL}^{-1}$. Thus, a total of 23 subjects $(11.9 \%)$ had a significant increase in BHR (3.2-fold decrease in PC20). In contrast, using a less conservative criterion (a two-fold decrease in PC20), 29 subjects $(14.9 \%)$ had an increase in BHR. The mean decline in FEV1 \% pred in subjects with a significant decrease in PC20 (>3.2-fold decrease) was -10.7 compared to $-8.13 \%$ among the other subjects $(\mathrm{p}=0.21)$.

Table 4 illustrates the distribution of subjects with at least one welding-related symptom according to whether or not they showed an increase in bronchial responsiveness. The incidence of welding-related respiratory symptoms suggestive of OA was $13.8 \%$ throughout the study with participants experiencing more cough $(9.9 \%)$ than wheezing or chesttightness (5.2 and 5.6\%, respectively). Seven subjects persistently reported having at least one of the following symptoms: cough, wheezing and chest-tightness (data not shown). Of the 20 subjects who had $\mathrm{a} \geqslant 3$.2-fold decrease in PC20 from the baseline value, five apprentices had persistent respiratory symptoms suggestive of OA. Thus, the incidence of probable OA was in the order of nearly $3 \%$ (6 of 194 or 5 of 194) when there was either a two-fold or a $\geqslant 3$.2-fold decrease in PC20 from one visit to the next.

Table 5 presents a detailed description of probable cases of OA. It shows that three apprentices with normal airway responsiveness at baseline had a significant reduction in their PC20 by the end of the study. The other three apprentices with pre-existing airway hyperresponsiveness had a further deterioration expressed by $\mathrm{a} \geqslant 3$.2-fold reduction in their PC20. Apprentices mostly reported the presence of welding-related respiratory symptoms suggestive of $\mathrm{OA}$ at the second followup, particularly symptoms of cough and chest-tightness. Only one apprentice-welder reported having a physician-diagnosis of asthma.

Table 1.-Respiratory symptomatology, spirometry and bronchial challenge test results

\begin{tabular}{|c|c|c|c|c|c|}
\hline & $\mathrm{n} /$ total n $(\%)$ & Baseline & End of study & Mean difference & p-value \\
\hline Baseline non-W-R RS & 34 (17.5) & & & & \\
\hline W-R RS at 1st follow-up & $12 / 187(6.4)$ & & & & \\
\hline W-R RS at end of study & $14 / 193(7.3)$ & & & & \\
\hline $\begin{array}{l}\text { W-R RS at 1st follow-up } \\
\text { and/or end of study }\end{array}$ & $24 / 194(12.4)$ & & & & \\
\hline Persistent W-R RS & $14 / 184(7.6)$ & & & & \\
\hline FEV $1 \mathrm{~L} \cdot \mathrm{min}^{-1}$ & & $4.35 \pm 0.87$ & $4.01 \pm 0.84$ & $-0.34 \pm 0.35$ & $<0.01^{+}$ \\
\hline FVC & & $5.09 \pm 0.98$ & $4.67 \pm 0.93$ & $-0.43 \pm 0.42$ & $<0.01^{+}$ \\
\hline FEV1 $\%$ pred & & $106.48 \pm 15.68$ & $98.05 \pm 15.88$ & $-8.44 \pm 9.19$ & $<0.01^{+}$ \\
\hline FVC $\%$ pred & & $103.82 \pm 21.76$ & $97.18 \pm 14.16$ & $-7.80 \pm 15.18$ & $<0.01^{+}$ \\
\hline FEV $1 / F V C \%$ pred & & $100.32 \pm 8.18$ & $101.54 \pm 7.53$ & $+0.99 \pm 5.32$ & $0.01^{+}$ \\
\hline Log slope & & $1.55 \pm 0.52$ & $1.64 \pm 0.55$ & $0.09 \pm 0.31$ & $<0.01^{+}$ \\
\hline FEV1 \% pred $<80 \%$ n $(\%)$ & & 73.6 & 22 & 11.3 & $<0.01^{\S}$ \\
\hline FEV $1 /$ FVC $\%$ pred $<85 \%$ n ( $\%)$ & & 94.8 & 4 & 2.1 & NS \\
\hline $\mathrm{PC} 20 \leqslant 8 \mathrm{mg} \cdot \mathrm{mL}^{-1} \mathrm{n}(\%)$ & & 2814.4 & 36 & 18.6 & $<0.05^{\S}$ \\
\hline $\mathrm{PC}_{20} \leqslant 16 \mathrm{mg} \cdot \mathrm{mL}^{-1} \mathrm{n}(\%)$ & & 3920.1 & 46 & 23.7 & NS \\
\hline
\end{tabular}

Data are presented as mean \pm SD, unless otherwise stated; $n=194$; A total 92 apprentices did not have the methacholine bronchial challenge test ( 82 dropped out, eight refused to do the test and two students did not do the test at visit 1). W-R: welding-related; RS: respiratory symptoms; FEV1: forced expiratory volume in one second; FVC: forced vital capacity; NS: nonsignificant; PC20: provocative concentration causing a $20 \%$ fall in the FEV1. " : cases include subjects that developed at least one W-R RS suggestive of occupational asthma (OA) at least once during the study; ${ }^{\uparrow}$ : cases include subjects that developed at least one W-R RS suggestive of OA at first follow-up that persisted until the second follow-up or the development of at least one W-R RS as of the second follow-up; ${ }^{+}$: p-value in a paired-samples t-test; ${ }^{\S}$ : $p$-value in a McNemar test; $n=194$. 
Table 2. - Distribution of subjects with a forced expiratory volume in one second (FEV 1$) \%$ predicted $<80 \%$ at the end of the study according to bronchial responsiveness and $\mathrm{FEV}_{1} \%$ pred at baseline

\begin{tabular}{|c|c|c|c|c|c|c|}
\hline \multirow[t]{3}{*}{ End of study FEV $1<80 \%$ pred } & \multicolumn{2}{|c|}{$\mathrm{PC} 20 \leqslant 16 \mathrm{mg} \cdot \mathrm{mL}^{-1}$} & \multicolumn{2}{|c|}{$\mathrm{PC} 20>16 \mathrm{mg} \cdot \mathrm{mL}^{-1}$} & \multicolumn{2}{|c|}{ All } \\
\hline & \multicolumn{2}{|c|}{ Baseline FEV $1<80 \%$ pred } & \multicolumn{2}{|c|}{ Baseline FEV1 $<80 \%$ pred } & \multicolumn{2}{|c|}{ Baseline FEV $1<80 \%$ pred } \\
\hline & Yes & No & Yes & No & Yes & No \\
\hline Yes & $6(100)$ & $5(15.2)$ & $1(100)$ & $10(6.5)$ & $7(100)$ & $15(8.0)$ \\
\hline No & 0 & $28(84.8)$ & 0 & $144(93.5)$ & 0 & $172(92)$ \\
\hline Total & 6 & 33 & 1 & 154 & 7 & 187 \\
\hline
\end{tabular}

Data are presented as $\mathrm{n}(\%)$ or $\mathrm{n}$. PC20: provocative concentration causing a $20 \%$ fall in FEV1.

Table 3. - Change in bronchial responsiveness in apprentices 15 months after starting exposure to welding fumes

\begin{tabular}{lccc}
\hline & \multicolumn{2}{c}{ PC20 } \\
\cline { 3 - 4 } & & $\begin{array}{c}\text { 2-fold } \\
\text { decrease }\end{array}$ & $\begin{array}{c}\text { 3.2-fold } \\
\text { decrease }\end{array}$ \\
\hline $\begin{array}{l}\text { New cases of BHR } \\
\text { Cases with deterioration }\end{array}$ & $+/+$ & $13(6.7)$ & $13(6.7)$ \\
$\quad$ of BHR & & $16(8.2)$ & $10(5.2)$ \\
$\begin{array}{l}\text { Total } \\
\text { Normalisation of BR }\end{array}$ & +- & $29(14.9)$ & $23(11.9)$ \\
No change in BR & $+/+$ & $17(8.8)$ & $6(3.1)$ \\
Normal BR throughout & - & $142(73.2)$ & $142(73.2)$ \\
\hline
\end{tabular}

Data are presented as $\mathrm{n}(\%)$. Ten students refused to do the test at the third visit (two of them had not done the test initially at visit 1); PC20: provocative concentration causing a $20 \%$ fall in the forced expiratory volume in one second; BHR: bronchial hyperresponsiveness; BR: bronchial responsiveness. - : PC20 $>16 \mathrm{mg} \cdot \mathrm{mL}^{-1} ;+:$ PC $20 \leqslant 16 \mathrm{mg} \cdot \mathrm{mL}^{-1} ;++$ : baseline PC20 $\leqslant 16 \mathrm{mg} \cdot \mathrm{mL}^{-1}$ and a $\geqslant$ two-fold decrease in PC20; $\mathrm{n}=194$.

\section{Discussion}

To the best of the authors' knowledge, this is the first prospective study to measure the incidence of airway obstruction, BHR and OA in apprentices newly exposed to welding fumes and gases. It was found that: 1) FEV1 \% pred dropped significantly (by $8.4 \%$ on average) from the pre-exposure baseline value; 2) 23 apprentices $(11.9 \%)$ had a significant increase in BHR when it was defined as a $\geqslant 3$.2-fold decrease from baseline $\mathrm{PC} 20$ and; 3 ) the incidence of probable OA, using a definition that the authors proposed, was nearly $3 \%$.

The drop in FEV1 \% pred was important but probably cannot be attributed to a chronic effect of exposure to welding fumes and gases, given the relatively short duration of the welding training programme. The tests undertaken were being performed at the teaching institutions during a normal class day. Although some authors found no significant differences between lung function changes over the day between welders and controls [6, 25-27], others have found significant decreases from morning to afternoon in the mean change in FEV1 and FVC among both welders and controls, but the reduction was almost four-times greater among welders [3] where in the latter study welders who had the reduction in the pulmonary function indices did not differ from those without reductions in terms of age, height, baseline lung function or smoking habits.

In the present study, spirometry and methacholine tests were performed on two occasions, 15 months apart on average, first before the apprentices started exposure to welding fumes and gases, and again at the end of the vocational training. The effect of independent factors (i.e. day of the week the test was carried out, baseline airway responsiveness and smoking) on the decrease in FEV1, \% pred, other than exposure, was examined. Assuming that a weekly effect would be present, the proportion of subjects with a drop in FEV1\% pred would have to be greater for those who had a test performed between Tuesday and Friday at the end of the welding training programme. On the contrary, when taking into consideration whether the second methacholine test was done on a Monday or another day of the week, there was still a significant drop in FEV1 \% pred $(9.87 \pm 10.15 \%$ and $8.20 \pm 9.05 \%$, respectively), regardless of the day of the week on which the follow-up test was performed. Upon considering whether having BHR at baseline would be associated with a decrease in FEV1 \% pred value; the results showed very similar changes in mean decline FEV1 whatever the level of bronchial responsiveness at baseline. With regard to the drop in FEV1 \% pred $<80 \%$ the proportion of subjects with baseline $\mathrm{PC} 20 \leqslant 16 \mathrm{mg} \cdot \mathrm{mL}^{-1}$ (the present criteria for $\mathrm{BHR}$ ) was greater than that with $\mathrm{PC} 20>16 \mathrm{mg} \cdot \mathrm{mL}^{-1}$ suggesting an association, although not significant; the lack of significance could be due to a lack of statistical power, since the numbers of subjects with a drop in FEV1 \% pred $<80 \%$ was small $(n=15)$. Finally, there was no significant difference in the mean decline in FEV1 \% pred between smokers $(8.92 \pm 8.97 \%)$ and nonsmokers $(8.02 \pm 9.40 \%)$. Deterioration in pulmonary function among welders compared with a reference group

Table 4.-Distribution of subjects with at least one welding-related respiratory symptom (W-R RS) according to an increase in bronchial responsiveness (BR)

\begin{tabular}{lrrrr}
\hline & \multicolumn{2}{c}{ Increase in BR (2-fold) } & \multicolumn{2}{c}{ Increase in BR (3.2-fold) } \\
\cline { 2 - 4 } & \multicolumn{1}{c}{ Yes } & No & Yes \\
\hline RS at 1st follow-up & $5 / 27(18.5)$ & $7 / 160(4.4)$ & & No \\
RS at 2nd follow-up & $6 / 29(20.7)$ & $8 / 164(4.9)$ & $5 / 21(19.0)$ & $8 / 166(4.8)$ \\
Nonpersistent RS & $10 / 29(34.5)$ & $14 / 165(8.5)$ & $8 / 23(34.8)$ & $9 / 170(5.3)$ \\
Persistent RS & $6 / 25(24.0)$ & $8 / 159(5.0)$ & $5 / 20(25.0)$ & $9 / 171(9.4)$ \\
\hline
\end{tabular}

Data are presented as $\mathrm{n} /$ total $\mathrm{N}(\%) .{ }^{\#}$ : some subjects did not have complete questionnaire data; ${ }^{\circ}$ : cases include subjects that developed at least one W-R RS suggestive of occupational asthma (OA) at least once during the study; ${ }^{+}$: cases include subjects that developed at least one W-R RS suggestive of OA at first follow-up that persisted until the second follow-up or the development of at least one W-R RS as of the second follow-up. 
Table 5. - Selected features of cases of probable occupational asthma\#

\begin{tabular}{|c|c|c|c|c|c|c|c|c|c|}
\hline \multirow[t]{2}{*}{ Cases } & \multirow[t]{2}{*}{ Age yrs } & \multirow[t]{2}{*}{ Sex } & \multirow[t]{2}{*}{ Asthma $^{+}$} & \multicolumn{2}{|r|}{ W-R RS } & \multicolumn{2}{|c|}{$\mathrm{FEV} 1 \mathrm{~L} \cdot \mathrm{min}^{-1}$} & \multicolumn{2}{|c|}{$\mathrm{PC} 20 \mathrm{mg} \cdot \mathrm{mL}^{-1}$} \\
\hline & & & & 1st follow-up & 2nd follow-up & Baseline & Follow-up & Baseline & Follow-up \\
\hline 1 & 35 & $\mathrm{~F}$ & No & None & Cough, wheezing, chest-tightness & 2.13 & 1.84 & 4.9 & 0.92 \\
\hline 2 & 46 & M & No & None & Cough & 4.30 & 3.75 & 9.9 & 1.15 \\
\hline 3 & 22 & M & No & Chest-tightness & Cough, chest-tightness & 5.11 & 5.11 & $>32$ & 8.9 \\
\hline 4 & 34 & $\mathrm{~F}$ & No & None & Cough, chest-tightness & 3.08 & 3.14 & $>32$ & 15.5 \\
\hline 5 & 22 & M & No & None & Cough, chest-tightness & 5.57 & 4.82 & $>32$ & 4.0 \\
\hline 6 & 20 & M & Yes & None & Cough, wheezing & 3.72 & 3.41 & 11.0 & 3.5 \\
\hline
\end{tabular}

W-R: welding-related; RS: respiratory symptoms; FEV1: forced expiratory volume in one second; PC20: provocative concentration causing a $20 \%$ fall in the FEV1; F: female; M: male. ${ }^{\#}$ : cases include subjects that developed at least one W-R RS suggestive of occupational asthma at first follow-up that persisted until the second follow-up or the development of at least one W-R RS as of the second follow-up with a two-fold or a $\geqslant 3.2$-fold decrease in PC20 between the baseline and end of study; ${ }^{+}$: physician-diagnosed asthma at baseline; $n=6$.

[2-9], has been previously noted in epidemiological studies, with greater effects observed in smokers $[6,13,27,28]$, confirming the role of smoking as the main risk factor leading to the decline in lung function. The absence of an influence of smoking in this study could be partly explained by the current study subjects being young adults who consequently would not have been significantly affected by respiratory conditions due to cigarette smoking. Moreover, the same well-maintained instruments and a standardised procedure for performing spirometric and bronchial responsiveness tests were used. Hence, the authors believe that the demonstrated functional impairment of the apprentice welders most probably reflects actual changes in the level of bronchial calibre and that the exposure to welding gases and fumes does appear to decrease pulmonary function parameters acutely in this context.

When comparing the 10 subjects with a baseline PC20 $>16 \mathrm{mg} \cdot \mathrm{mL}^{-1}$, who had a drop in their FEV $1 \%$ pred $<80 \%$, to the 144 students who did not have that drop it seems that from the start the former had, on average, significantly lower values of FEV1 \% pred $(90.93 \pm 5.86 \%$ and $110.69 \pm 12.90 \%$, respectively). By considering these 10 subjects separately, it is found that one-half of them had a FEV1 \% pred $<90 \%$. Three were current smokers who also reported symptoms suggestive of asthma at baseline. It was found that two of these three also became hyperresponsive to the methacholine challenge. One of these two was a smoker who reported having had asthma diagnosed by a doctor, and who had wheezing and chest-tightness in the year prior to the baseline interview as well as at the last follow-up and metal fume fever. However, this subject did not report any welding-related respiratory symptoms.

In the current study, $\sim 29 \%$ of the apprentices were lost to follow-up with the majority having quit the apprenticeship shortly following the baseline assessment survey. Although these were not contacted, it is believed that the short duration between enrolling and dropping out excludes possible selfselection out of the apprenticeship because of welding-related health complaints after entry into the programme. Those who were lost to follow-up in the current study did not differ in terms of baseline demographical characteristics from those who remained until the end of apprenticeship. Close examination of baseline symptomatology revealed that a significantly higher proportion of apprentices lost to follow-up had phlegm, while a significantly lower proportion of apprentices lost to follow-up had a personal atopic history (history of eczema, urticaria, or hay fever), rhinitis with pets and in the pollen season, as well as respiratory symptoms with pets.

An interesting finding of this study was that the incidence of BHR was higher than that of OA. As many as $75 \%$ (15 of 20) of the apprentices who had a 3.2- fold decrease in $\mathrm{PC} 20$ had no persistent welding-related respiratory symptoms suggestive of OA, although eight of 15 subjects reported respiratory symptoms at one of the follow-up visits. Increased bronchial reactivity to nonspecific bronchoconstricting stimuli is a characteristic property of asthma, but BHR does not constitute asthma and is found in some individuals with no history or symptoms of asthma [23, 29]. Approximately $50 \%$ of subjects with airway hyperresponsiveness report no respiratory symptoms [30, 31]. In a 3-yr followup study [32], subjects with airway hyperresponsiveness and no respiratory symptoms had a greater increase in airway responsiveness and incidence of asthma symptoms than symptomatic asthmatic subjects or normoresponsive controls. These authors, along with others [33], suggested that airway hyperresponsiveness appears to be an intermediate stage between normality and symptomatic asthma. More recently, GAUTRIN et al. [34] in a prospective study of 417 apprentices in animal-health technology have shown that pre-exposure airway calibre and responsiveness are associated with an increased risk of developing probable OA.

In this study, the criteria for defining probable cases of OA included the presence of welding-related respiratory symptoms together with BHR upon considering previous definitions for asthma and OA. TOELLE et al. [35] defined current or common asthma as BHR plus recent wheeze (occurring in the last 12 months prior to the study) for measuring the prevalence of clinically important asthma in populations. OA has been defined as "a disease characterised by variable airflow limitation and/or BHR due to causes and conditions attributable to a particular occupational environment and not to stimuli encountered outside the workplace" [36]. Clinically, OA is manifested by work-related symptoms of chest-tightness, wheezing and cough, while physiologically, there are alterations in lung mechanics that change with time [37]. In a previous prospective study among apprentices exposed to laboratory animals, the incidence of probable OA was found to be in the order of $2.7 \%$ [34]. The incidence of OA that was found in apprentice welders is very close to this. In the quoted study, probable OA was defined as the onset of immediate skin reactivity to one or more occupational inhalants together with $a \geqslant 3$.2-fold decrease in PC20. Moreover, it has been reported recently that the sensitivity of clinical history, nonspecific BHR, and skin-prick tests against natural rubber latex (high molecular-weight agent) in the clinical assessment of OA, are in the order of 87,90 and $100 \%$, respectively [38].

\section{Conclusion}

Overall, the prospective study provided increasing evidence that exposure to welding fumes and gases is associated with pulmonary functional changes and respiratory symptoms in welders. These changes have been seen in the apprentices over 
an average short period of 15 months. Since apprentices will become newly hired welders and thus part of the future welding population, it is relevant to examine whether these changes represent a predisposing factor to further chronic abnormalities.

\begin{abstract}
Acknowledgements. The authors acknowledge the collaboration of the administration and the professors of the participating teaching institutions as well as all apprentice welders who took part in the study. They specifically wish to thank the technicians, especially C. Trudeau and S. Chaboillez and nurse M. Magnan, responsible for data collection. The authors express their appreciation of the statistical expertise provided by H. Ghezzo. Finally, the authors thank L. Schubert for revising the manuscript.
\end{abstract}

\section{References}

1. Sferlazza S, Beckett W. The respiratory health of welders. Am Rev Respir Dis 1991; 143: 1134-1148.

2. Mur J, Teculescu D, Pham Q, et al. Lung function and clinical findings in a cross-sectional study of arc welders. Int Arch Occup Environ Health 1985; 57: 1-17.

3. Akbar-Khanzadeh F. Short-term respiratory function changes in relation to workshift welding fume exposure. Int Arch Environ Health 1993; 64: 393-397.

4. Rastogi S, Gupta B, Husain T, Mathur N, Srivastava S. Spirometric abnormalities among welders. Env Res 1991; 56: $15-24$.

5. Lyngenbo $\mathrm{O}$, Groth $\mathrm{S}$, Groth $\mathrm{M}$, Olsen $\mathrm{O}$, Rossing $\mathrm{N}$. Occupational lung function impairment in never-smoking Danish welders. Scan J Soc 1989; 17: 157-164.

6. Kilburn KH, Warshaw R, Boylen CT, et al. Cross-shift and chronic effects of stainless-steel welding related to internal dosimetry of chromium and nickel. Am J Ind Med 1990; 17: 607-615.

7. Ozdemir O, Numanoglu N, Gonullu U, Savas I, Alper D, Gurses H. Chronic effects of welding exposure on pulmonary function tests and respiratory symptoms. Occup Environ Med 1995; 52: 800-803.

8. Wang ZP, Larsson K, Malmberg P, Sjogren B, Hallberg BO, Wrangskog K. Asthma, lung function, and bronchial responsiveness in welders. Am J Ind Med 1994; 26: 741-754.

9. Erhabor GE, Fatusi S, Obembe OB. Pulmonary functions in arc-welders in Ile-Ife, Nigeria. East Afr Med $J$ 2001; 78: 461-464.

10. Kilburn K, Warshaw R. Pulmonary functional impairment from years of arc welding. Am J Med 1989; 87: 62-69.

11. Fishwick D, Pearce N, D'Souza W, et al. Occupational asthma in New Zealanders: a population based study. Occup Environ Med 1997; 54: 301-306.

12. Erkinjuntti-Pekkanen R, Slater T, Cheng S, et al. Two year follow up of pulmonary function values among welders in New Zealand. Occup Environ Med 1999; 56: 328-333.

13. Chinn DJ, Cotes JE, el Gamal FM, Wollaston JF. Respiratory health of young shipyard welders and other tradesmen studied cross sectionally and longitudinally. Occup Environ Med 1995; 52: 33-42.

14. Beckett WS, Pace PE, Sferlazza SJ, Perlman GD, Chen AH, $\mathrm{Xu}$ XP. Airway reactivity in welders: a controlled prospective cohort study. J Occup Environ Med 1996; 38: 1229-1238.

15. Burney $\mathrm{P}$, Laitinen L, Perdrizet $\mathrm{S}$, et al. Validity and repeatability of the IUATLD (1984) bronchial symptoms questionnaire: an international comparison. Eur Respir $J$ 1989; 2: 940-945.

16. American Thoracic Society (ATS). Standardization of spirometry. Am J Respir Crit Care Med 1995; 152: 1136.

17. Cockcroft D, Killian D, Mellon J, Hargreave F. Bronchial reactivity to inhaled histamine: a method and clinical survey. Clinical Allergy 1977; 7: 235-243.

18. Sterk P, Fabbri L, Quanjer P, et al. Airway responsiveness. Standardized challenge testing with pharmacological, physical and sensitizing stimuli in adults. Report working party standardization of lung function tests European Community for Steel and Coal. Official statement of the European Respiratory Society. Eur Respir J 1993; 6: Suppl. 16, 53-83.

19. Troyanov S, Malo J, Cartier A, Gautrin D. Frequency and determinants of exaggerated bronchoconstriction during shortened methacholine challenge tests in epidemiological and clinical set-ups. Eur Respir J 2000; 16: 9-14.

20. Knudson R, Lebowitz M, Holberg C, Burrows B. Changes in the normal maximal expiratory flow-volume curve with growth and aging. Am Rev Respir Dis 1983; 127: 725-734

21. Malo J, Pineau L, Cartier A, Martin R. Reference values of the provocative concentrations of methacholine that cause $6 \%$ and $20 \%$ changes in forced expiratory volume in one second in a normal population. Am Rev Respir Dis 1983; 128: 8-11.

22. Dehaut P, Rachiele A, Martin R, Malo J. Histamine doseresponse curves in asthma: reproducibility and sensitivity of different indices to assess response. Thorax 1983; 38: 516-522.

23. O'Connor GT, Weiss ST, Speizer FE. The epidemiology of asthma. In: Gershwin ME, ed. Bronchial Asthma: Principles of Diagnosis and Treatment. Florida, USA, Grune and Stratton, 1986; 3-18.

24. Chinn S, Burney D, Jarvis C, Luczynska C. Variation in bronchial responsiveness in the European community respiratory health survey (ECRHS). Eur Respir J 1997; 10: 2495-2501.

25. McMillan G, Health J. The health of welders in naval dockyards: Acute changes in respiratory function during standardized welding. Ann Occup Hyg 1979; 22: 19-32.

26. Marquart H, Smid T, Heederik D, Visschers M. Lung function of welders of zinc-coated mild steel: cross-sectional analysis and changes over five consecutive work shifts. Am J Indus Med 1989; 16: 289-296.

27. Kilburn K, Warshaw R, Boylen C, Thornton J. Respiratory symptoms and functional impairment from acute (crossshift) exposure to welding gases and fumes. $\mathrm{Am} \mathrm{J} \mathrm{Med} \mathrm{Sc}$ 1989; 298: 314-319.

28. Chinn DJ, Stevenson IC, Cotes JE. Longitudinal respiratory survey of shipyard workers: effects of trade and atopic status. Br J Ind Med 1990; 47: 83-90.

29. Cartier A. Definition and diagnosis of occupational asthma Eur Respir J 1994; 7: 153-160.

30. Cockcroft D, Berscheid B, Murdock K. Bronchial response to inhaled histamine in asymptomatic young smokers. Eur J Respir Dis 1983; 64: 207-211.

31. Woolcock A. What is bronchial hyperresponsiveness from the clinical standpoint. In: Page CP, Phillip J, eds. Airway Hyperresponsiveness: is it really important for asthma. Oxford, Boston Blackwell Scientific, 1993; pp. 1-9.

32. Laprise C, Boulet LP. Asymptomatic airway hyperresponsiveness: a three-year follow-up. Am J Respir Crit Care Med 1997; 156: 403-409.

33. Hopp R, Robert G, Townley R, Biven R, Bewtra A, Nair N. The presence of airway reactivity before the development of asthma. Am Rev Respir Dis 1990; 141: 2-8.

34. Gautrin D, Infante-Rivard C, Ghezzo H, Malo J. Incidence and host determinants of probable occupational asthma in apprentices exposed to laboratory animals. Am J Respir Crit Care Med 2001; 163: 899-904.

35. Toelle B, Peat J, Salome C, Mellis C, Woolcock A. Toward a definition of asthma for epidemiology. Am Rev Respir Dis 1992; 146: 633-637.

36. Bernstein I, Chan-Yeung M, Malo J, Berstein D. Asthma in the Workplace. 2nd ed. New York, Marcel Dekker Inc., 1999.

37. Brooks SM. Occupational asthma. In: Weiss EB, Stein M, eds. Bronchial Asthma: Mechanisms and Therapeutics. Boston, USA, Little, Brown and Company, 1993; pp. 585-611.

38. Vandenplas $\mathrm{O}$, Cangh FB-V, Brumagne A, et al. Occupational asthma in symptomatic workers exposed to natural 